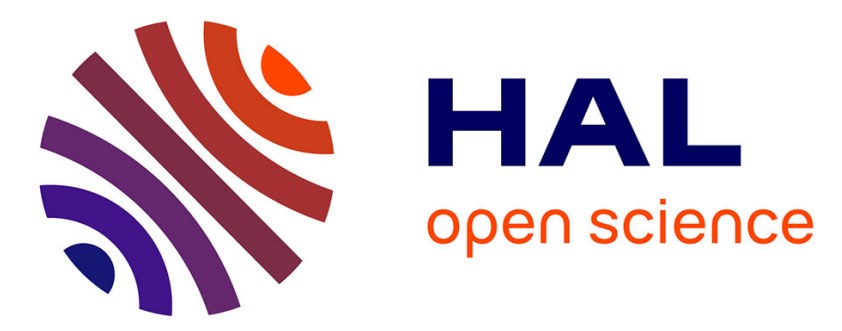

\title{
Deposition of hard thin films from HMDSO in atmospheric pressure dielectric barrier discharge
}

D Trunec, L Zajková, V Buršková, F Studnika, P S Ahel, V Prysiazhnyi, V Peřina, J Houdková, Z Navrátil, D Franta

\section{- To cite this version:}

D Trunec, L Zajková, V Buršková, F Studnika, P S Ahel, et al.. Deposition of hard thin films from HMDSO in atmospheric pressure dielectric barrier discharge. Journal of Physics D: Applied Physics, 2010, 43 (22), pp.225403. 10.1088/0022-3727/43/22/225403 . hal-00569620

\section{HAL Id: hal-00569620 \\ https://hal.science/hal-00569620}

Submitted on 25 Feb 2011

HAL is a multi-disciplinary open access archive for the deposit and dissemination of scientific research documents, whether they are published or not. The documents may come from teaching and research institutions in France or abroad, or from public or private research centers.
L'archive ouverte pluridisciplinaire HAL, est destinée au dépôt et à la diffusion de documents scientifiques de niveau recherche, publiés ou non, émanant des établissements d'enseignement et de recherche français ou étrangers, des laboratoires publics ou privés. 


\title{
Deposition of hard thin films from HMDSO in atmospheric pressure dielectric barrier discharge
}

\author{
D Trunec ${ }^{1}$, L Zajíčková ${ }^{1}$, V Buršíková ${ }^{1}, \mathbf{F}$ Studnička $^{1}, \mathbf{P}$ \\ Sťahel $^{1}$, V Prysiazhnyi ${ }^{1}$, V Peřina ${ }^{2}$, J Houdková $^{3}$, Z Navrátil ${ }^{1}$ \\ and D Franta ${ }^{1}$ \\ ${ }^{1}$ Department of Physical Electronics, Faculty of Science, Masaryk University, \\ Kotlářská 2, 61137 Brno, Czech Republic \\ ${ }^{2}$ Institute of Nuclear Physics, Academy of Sciences of the Czech Republic, 25068 \\ Řež, Czech Republic \\ ${ }^{3}$ Institute of Physics, Academy of Sciences of the Czech Republic, Cukrovarnická 10, \\ 16253 Prague, Czech Republic \\ E-mail: trunec@physics.muni.cz
}

\begin{abstract}
The atmospheric pressure dielectric barrier discharge burning in nitrogen with small admixture of hexamethyldisiloxane (HMDSO) was used for the deposition of thin organosilicon films. The thin films were deposited on glass, silicon and polycarbonate substrates, the substrate temperature during the deposition process was elevated up to values within the range $25^{\circ} \mathrm{C}-150^{\circ} \mathrm{C}$ in order to obtain hard $\mathrm{SiO}_{x}$-like thin films. The properties of the discharge were studied by means of optical emission spectroscopy and electrical measurements. The deposited films were characterised by Rutherford backscattering and elastic recoil detection methods, x-ray photoelectron spectroscopy, infrared spectroscopy measurements, ellipsometry and depth sensing indentation technique. It was found that the films properties depend significantly on substrate temperature at deposition. An increase of substrate temperature from $25^{\circ} \mathrm{C}$ to $150^{\circ} \mathrm{C}$ leads to an increase of film hardness from $0.4 \mathrm{GPa}$ to $7 \mathrm{GPa}$ and the film chemical composition changes from $\mathrm{CH}_{x} \mathrm{Si}_{y} \mathrm{O}_{z}$ to $\mathrm{SiO}_{x} \mathrm{H}_{y}$. The films were transparent in visible range.
\end{abstract}

Submitted to: J. Phys. D: Appl. Phys.

PACS numbers: $52.80 \mathrm{Tn}, 52.77 \mathrm{Dq}$ 


\section{Introduction}

Dielectric barrier discharges (DBDs) are widely used for industrial purposes such as the modification of polymer surface properties, e. g. wettability or adhesion, owing to the possibility of the atmospheric pressure processing and the on-line treatment. Although this method is very useful, the main disadvantage of DBDs is lack of uniformity. This is due to the fact that at atmospheric pressure DBD is normally a filamentary discharge. Due to of this drawback an effort to homogenise DBDs has been made and it was found that under certain conditions homogeneous DBD can be obtained. A homogeneous DBD can be obtained in helium or neon and it is called atmospheric pressure glow discharge (APG discharge, APGD) [1,2]. Another type of homogeneous DBD can be obtained in nitrogen and this discharge type is called atmospheric pressure Townsendlike discharge (APTD) [3]. The uniformity of plasma favours these discharge types for thin film deposition techniques such as plasma enhanced chemical vapour deposition (PECVD). PECVD methods enable the preparation of coatings with a wide range of properties, e. g. wetting and sticking behaviour, mechanical, optical or electrical properties. The disadvantage of the low pressure PECVD techniques is the necessity to use expensive vacuum pumping systems. Moreover, the difficulties to arrange the deposition system for large area depositions have to be overcome. Recently plasma deposition at atmospheric pressure has become a promising technology due to its economical and ecological advantages. Sawada et al [4] reported the organosilicon thin films deposition in APGD in helium with the admixture of tetraethoxysilane (TEOS) or HMDSO and oxygen, Prat et al [5] reported fluoro-polymer film deposition in helium APGD with admixture of hexafluoropropylene or tetrafluoroethylene, Gherardi et al [6] used $\mathrm{N}_{2}-\mathrm{SiH}_{4}-\mathrm{N}_{2} \mathrm{O}$ APTD for $\mathrm{SiO}_{2}$ deposition, Foest et al [7] used APGD in helium with an admixture of HMDSO for organosilicon thin film deposition. Starostine et al [8] reported the silica-like coating deposition in APGD in argon, nitrogen, oxygen and HMDSO gas mixture. Recent reviews of theoretical understanding of homogeneous DBD can be found in $[9,10]$.

In the present paper APTD in nitrogen was used with a small admixture of hexamethyldisiloxane $\left(\mathrm{C}_{6} \mathrm{H}_{18} \mathrm{Si}_{2} \mathrm{O}-\mathrm{HMDSO}\right)$ for the deposition of thin films with desired mechanical and optical properties and surface energy. HMDSO is already widely used for $\mathrm{SiO}_{x}$ thin film deposition in different discharge types $[11,12,13,14]$. In a previous study it was possible to deposit thin films from HMDSO in nitrogen APTD [15]. However, the deposited films were polymer-like, their maximum hardness was $0.6 \mathrm{GPa}$ and contained about $40 \%$ of carbon. Because such films cannot be used as hard protective layers, procedures for obtaining harder films were needed. The first possibility is an annealing of deposited films. The annealing of deposited films increases their hardness up to $5 \mathrm{GPa}$ and the content of $\mathrm{Si}-\mathrm{O}-\mathrm{Si}$ groups increases also [16]. The second possibility is to add an oxidizer gas $\left(\mathrm{O}_{2}\right.$ or $\left.\mathrm{N}_{2} \mathrm{O}\right)$ to HMDSO. Massines et al [17] reported the deposition of $\mathrm{SiO}_{x}$ thin film in $\mathrm{N}_{2}$ - HMDSO - $\mathrm{N}_{2} \mathrm{O}$ APTD. In this case, $\mathrm{N}_{2} \mathrm{O}$ acts as oxidizer gas and it was possible to obtain $\mathrm{SiO}_{2}$-like material. However, this 
research found that the addition of $\mathrm{N}_{2} \mathrm{O}$ achieves an insufficient increase of film hardness. In the present paper we studied another possibility to increase the film hardness, namely the deposition at higher substrate temperatures.

\section{Experimental}

The experiments were carried out in a metallic discharge reactor with the dimensions $500 \mathrm{~mm} \times 500 \mathrm{~mm} \times 500 \mathrm{~mm}$. The discharge burned between two planar metal electrodes, the upper covered with Simax glass, $1.5 \mathrm{~mm}$ in thickness. The bottom electrode was rectangular with dimensions $150 \mathrm{~mm} \times 60 \mathrm{~mm}$, the upper electrode was circular with a diameter of $36 \mathrm{~mm}$. The bottom electrode could be heated using a heating spiral and the electrode temperature was measured with a thermocouple. The films were deposited on thin glass substrates with dimensions $160 \mathrm{~mm} \times 65 \mathrm{~mm} \times 1 \mathrm{~mm}$, polycarbonate $160 \mathrm{~mm} \times 65 \mathrm{~mm} \times 0.8 \mathrm{~mm}$ substrates and $500 \mu \mathrm{m}$ silicon wafers, 76 or $102 \mathrm{~mm}$ in diameter. The glass and polycarbonate substrates were placed directly on the bottom electrode. In the case of silicon ( $\mathrm{Si}$ ) substrate, a $1 \mathrm{~mm}$ thick glass plate was placed between the bottom electrode and $\mathrm{Si}$. The discharge gap between the substrate and the upper electrode was set to $0.5 \mathrm{~mm}$.

The films were deposited in homogeneous mode of DBD (APTD) from HMDSO vapours mixed with synthetic air and pure nitrogen. The 6 or $16 \mathrm{sccm}$ of synthetic air bubbled through liquid HMDSO in a glass bottle container. It was then mixed with the main nitrogen flow of $6 \mathrm{slm}$. The HMDSO flow rate was determined by weighting the liquid before and after the deposition. The concentration of HMDSO in nitrogen was $70 \mathrm{ppm}$ and $173 \mathrm{ppm}$ whereas the concentration of oxygen was $200 \mathrm{ppm}$ and $532 \mathrm{ppm}$ for the air flow rates of $6 \mathrm{sccm}$ and $16 \mathrm{sccm}$, respectively. The film homogeneity depended on the type of gas flow [18]. Configuration of gas supply was optimized in preliminary deposition experiments. The final set-up, used for the depositions discussed in this paper, was as follows. The working gas mixture was supplied through an inlet in the upper corner of the discharge reactor. The reactor was pumped out from the opposite bottom corner. The deposition uniformity was further improved by gas exhaustion of $50 \mathrm{sccm}$ through an opening in the centre of the upper electrode.

Before starting the experiments the discharge chamber was pumped down to a pressure of $20 \mathrm{~Pa}$ and then filled with nitrogen to a pressure of $101 \mathrm{kPa}$. Atmospheric pressure during the deposition was maintained by slight pumping. High voltage with a frequency of $6 \mathrm{kHz}$ was used for discharge generation. The type of discharge, as concerns filamentary or homogeneous mode, was determined from the current-voltage measurements recorded by the digital oscilloscope HP 54820A Infinium (500 MHz, $2 \mathrm{GS} / \mathrm{s})$. The input power to the $6 \mathrm{kHz}$ high voltage generator was $26 \mathrm{~W}$ for the homogeneous mode deposition on glass substrates. Maintenance of the homogeneous discharge mode restricted the input power as well as applied voltage in a small range, especially for Si and polycarbonate substrates. In this case, the input power ensuring the homogeneous mode was only $15 \mathrm{~W}$ and the flow of air bubbled through liquid HMDSO 
was only $6 \mathrm{sccm}$. The power consumed in the discharge was several watts depending on input power and used substrate [19]. Besides electrical measurements, the discharge was studied by means of the optical emission spectroscopy. The emission spectra were recorded with the Jobin-Yvon TRIAX 550 spectrometer equipped with a CCD detector.

The chemical structure of the films was studied by Fourier Transform Infrared Spectroscopy (FTIR) using a Bruker Vertex 80v spectrometer. The films deposited on Si were measured in transmittance mode taking bare Si substrate as a reference. The films on glass substrates were measured in attenuation total reflection (ATR) mode using diamond crystal (one ATR reflection, angle of incidence $45^{\circ}$ ). The sample compartment was evacuated down to $2.51 \mathrm{hPa}$ in both measurement modes. The resolution of the spectrometer was set to $4 \mathrm{~cm}^{-1}$.

The surface composition of the deposited films was studied by X-ray induced photoelectron spectroscopy (XPS) by means of an ADES-400 photoelectron spectrometer (VG Scientific, UK) using $\mathrm{Mg} \mathrm{K} \mathrm{K}_{\alpha}$ excitation $(1253.6 \mathrm{eV}$ ) at an incidence angle of $70^{\circ}$ and emission angle $0^{\circ}$ measured from the surface normal. Since the sampling depth of XPS is about $5 \mathrm{~nm}$, a surface contamination layer was removed by a short argon ion cleaning ( $5 \mathrm{keV}, 5 \mathrm{~min}$ ). Surface composition was determined from C $1 \mathrm{~s}, \mathrm{O} 1 \mathrm{~s}$, Si $2 \mathrm{p}$, and $\mathrm{N}$ 1s spectra for both, as-deposited and sputter-cleaned films.

The complete atomic composition was determined by ion beam methods combining Rutherford backscattering (RBS) and elastic recoil detection analysis (ERDA). The atomic fractions of $\mathrm{C}, \mathrm{O}$ and $\mathrm{Si}$ were measured by $\mathrm{RBS}$ using $2.4 \mathrm{MeV}$ protons perpendicularly bombarding the surface. The sensitivity to carbon content was enhanced using proton resonance effect at the energy of $1.74 \mathrm{MeV}$. ERDA and RBS with an incident beam of $2.75 \mathrm{MeV} \alpha$-particles at $75^{\circ}$ to the surface normal were simultaneously used to determine the percentage of $\mathrm{H}$. The measured spectra were evaluated by GISA [20] and SIMNRA [21] procedures.

The optical properties of the films on $\mathrm{Si}$ were investigated by ellipsometry combined with reflectometry. The associated ellipsometric parameters $I_{\mathrm{s}}, I_{\mathrm{CII}}$ and $I_{\text {cIII }}$, representing three coordinates on Poincaré sphere defined as $I_{\mathrm{s}}=\sin 2 \Psi \sin \Delta$, $I_{\mathrm{CII}}=\sin 2 \Psi \cos \Delta$ and $I_{\mathrm{cIII}}=\cos 2 \Psi$, were measured with a UVISEL Jobin Yvon ellipsometer at five angles of incidence $\left(55^{\circ}-75^{\circ}\right)$ in the spectral range $190-2000 \mathrm{~nm}$. The reflectance $R$ was measured with a Perkin Elmer Lambda 45 spectrometer within the spectral range 190-1000 $\mathrm{nm}$ at an angle of incidence of $6^{\circ}$. The fitting procedure utilized the least-squares method, i.e. minimizing squares of differences between measured optical quantities $R, I_{\mathrm{s}}, I_{\mathrm{CII}}$ and $I_{\text {cIII }}$ and their theoretical values calculated by $2 \times 2$ matrix formalism [22]. The models used for the calculation of theoretical values are briefly described in the next section.

The hardness and elastic modulus values were assessed from depth sensing indentation tests using a Fischerscope H100 tester with Vickers indenter. The load and the corresponding indentation depth were recorded as a function of time for both loading and unloading processes. The desired material parameters were obtained from analysis of loading and unloading curves. The indentation tests were carried out for 
several different indentation depths (i. e. several different applied loads) in order to map the mechanical properties of the film/substrate system from near surface up to the film-substrate interface. The applied load $L$ ranged from 1 to $100 \mathrm{mN}$ with the force resolution of $0.04 \mathrm{mN}$. The accuracy of the indentation depth measurement was $\pm 1 \mathrm{~nm}$. Each indentation test was repeated at least 16 times.

\section{Results and discussion}

\subsection{Discharge diagnostics}

The discharge diagnostics was done by electrical measurement and optical emission spectroscopy. The spectra were recorded in the range of 300-800 nm, but above $450 \mathrm{~nm}$ only the second spectral order was registered. The influence of electrode temperature on the discharge conditions, manifesting e.g. in the deposition rate and film hardness, was investigated with optical emission spectroscopy. The radiation coming from the discharge was recorded with a spectrometer during controlled continual decrease of electrode temperature. Other parameters were kept similar as during depositions (nitrogen flow $6 \mathrm{slm}$, synthetic air flow $6 \mathrm{sccm}$, applied voltage $17 \mathrm{kV}_{\mathrm{pp}}$, frequency of applied voltage $6.7 \mathrm{kHz}$ ). The spectra consisted of the nitrogen second positive system $\left(\mathrm{N}_{2}, C^{3} \Pi_{u} \rightarrow B^{3} \Pi_{g}\right)$, the first negative system $\left(\mathrm{N}_{2}^{+}, B^{2} \Sigma_{\mathrm{u}}^{+} \rightarrow X^{2} \Sigma_{\mathrm{g}}^{+}\right)$and of $\mathrm{CN}$ violet system $\left({ }^{2} \Pi \rightarrow{ }^{2} \Sigma\right)$. The integrated intensities of $0-2$ band of the nitrogen second positive system at $380 \mathrm{~nm}, 0-0$ band of the nitrogen first negative system at $391 \mathrm{~nm}$ and 1-1 band of CN are plotted against electrode temperature in figure 1. The CN 1-1 band was chosen in order to avoid the inclusion of overlapping nitrogen bands.

The intensities of the bands strongly depended on electrode temperature, especially in the low temperature region. While the intensity of $\mathrm{N}_{2}$ band increases linearly with the electrode temperature, $\mathrm{CN}$ band intensity increases at first quickly and then it becomes saturated at high electrode temperatures. Thus maximum at approx. $60{ }^{\circ} \mathrm{C}$ is observed in their intensity ratio $\mathrm{CN} / \mathrm{N}_{2}$.

The bands of the second positive system of nitrogen $\mathrm{N}_{2}$ 0-2, $\mathrm{N}_{2} 1-3$ and $\mathrm{N}_{2} 2-4$ were used to calculate vibrational temperature. Determined vibrational temperature was at about $1720 \pm 20 \mathrm{~K}$ and it this not depend substantially on electrode temperature.

\subsection{Chemical structure and composition of films}

The chemical structure and composition of the deposited films were assessed by comparison with FTIR spectroscopy, XPS or RBS combined with ERDA. The films deposited on Si substrates using $6 \mathrm{sccm}$ of air bubbling through liquid HMDSO were studied by FTIR transmittance measurements and RBS/ERDA methods. Since the glass substrates are not transparent in IR range, the films on glass deposited with the air flow rate of 16 sccm were investigated by FTIR-ATR spectroscopy. Additionally, these films were studied by XPS. The chemical structure of the films and its evolution 
with increased deposition temperature was similar for both substrates and air flow rates. The details are discussed below.

3.2.1. Films on silicon substrates - air flow rate of 6 sccm The IR absorbances for the films on $\mathrm{Si}$ deposited at $25,50,75$ and $150^{\circ} \mathrm{C}$ are compared in figure 2 . The spectra show three characteristic peaks of silica at 440-450, 802-810 and 1043$1072 \mathrm{~cm}^{-1}$ corresponding to the rocking, bending and antisymetric stretching vibrations of the Si-O-Si groups, respectively [23]. The position of the stretching peak shifts significantly to higher wavenumbers with increased deposition temperature. This can be caused by several effects such as geometrical reasons, i. e., different film thickness, oxygen deficiency, material densification or carbon admixture. The first reason can be disregarded because the film thicknesses were similar (about $450 \mathrm{~nm}$ ). Oxygen deficiency causes the shift of this peak to lower wavenumbers [24, 25]. Studies of plastically densified $\mathrm{SiO}_{2}$ showed the shift of Si-O-Si stretching peak to higher wavenumbers with increased film density [26]. Some authors relate the absorption in the range 1000$1100 \mathrm{~cm}^{-1}$ to Si-O-C groups [27, 28, 29] and Aumaille et al observed downshift of this peak with increased organic content in the $\mathrm{HMDSO} / \mathrm{O}_{2}$ deposited films [30]. The results of RBS/ERDA analyses showed that the carbon content decreased with temperature from 23 to $2.5 \%$ (figure 3) and the density increased from 1.0 to $2.0 \mathrm{~g} \mathrm{~cm}^{-3}$ (figure 4 ). Additionally, there is an oxygen deficiency at $25^{\circ} \mathrm{C}$ because the $\mathrm{O} / \mathrm{Si}$ ratio is only 1.4 .

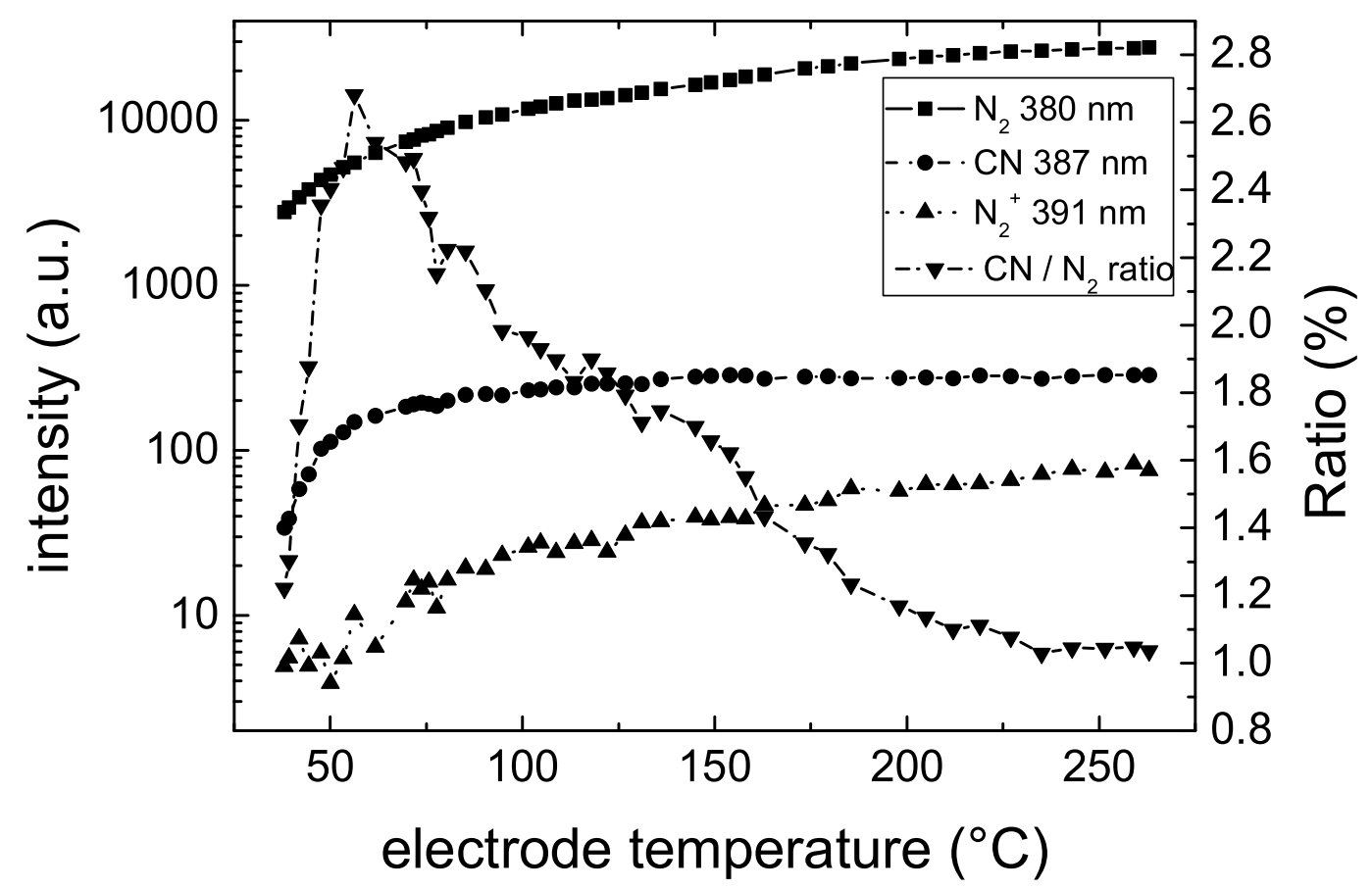

Figure 1. The dependence of different band intensities (derived from OES) and their ratios on electrode temperature. 
All these results are, therefore, consistent with observed shift of the peak from 1043 to $1072 \mathrm{~cm}^{-1}$. It should be noted that its position for the $400 \mathrm{~nm}$ thick thermally grown film was observed by Martinet et al [23] at $1089 \mathrm{~cm}^{-1}$.

Hydrocarbon groups can be responsible for part of the absorption in the region around $800 \mathrm{~cm}^{-1}$ in the case of low deposition temperature at which the carbon and hydrogen percentages were quite high (figure 3). A single peak at $810 \mathrm{~cm}^{-1}$ detected for $150^{\circ} \mathrm{C}$ film was obviously composed of minimally three peaks at about 782,802 and $840 \mathrm{~cm}^{-1}$ for the temperatures $25-75^{\circ} \mathrm{C}$. Their positions corresponded to $\mathrm{CH}_{3}$ rocking or Si-C stretching in $\mathrm{Si}-\left(\mathrm{CH}_{3}\right)_{x}$ groups $(x=1 \ldots 3)[27,31,32]$. Further evidence of methylsilyl groups was revealed by a narrow peak at $1273-1281 \mathrm{~cm}^{-1}$ and weak peak at $1410 \mathrm{~cm}^{-1}$ associated with symmetric and asymmetric bending of $\mathrm{Si}-\left(\mathrm{CH}_{3}\right)_{x}$, respectively $[31,33]$. The former peak was quite strong for all the low temperature films but almost diminished at $150^{\circ} \mathrm{C}$. The latter weak peak and weak peak at $2970 \mathrm{~cm}^{-1}$ associated with assymetric stretching of $\mathrm{CH}_{3}[31,34]$ were observable only for $25-75^{\circ} \mathrm{C}$. A weak broad peak at about $1360 \mathrm{~cm}^{-1}$ detected for $25^{\circ} \mathrm{C}$ was assigned to bending of $\mathrm{CH}_{2}$ in $\mathrm{Si}-\mathrm{CH}_{2}-\mathrm{Si}[31,33]$.

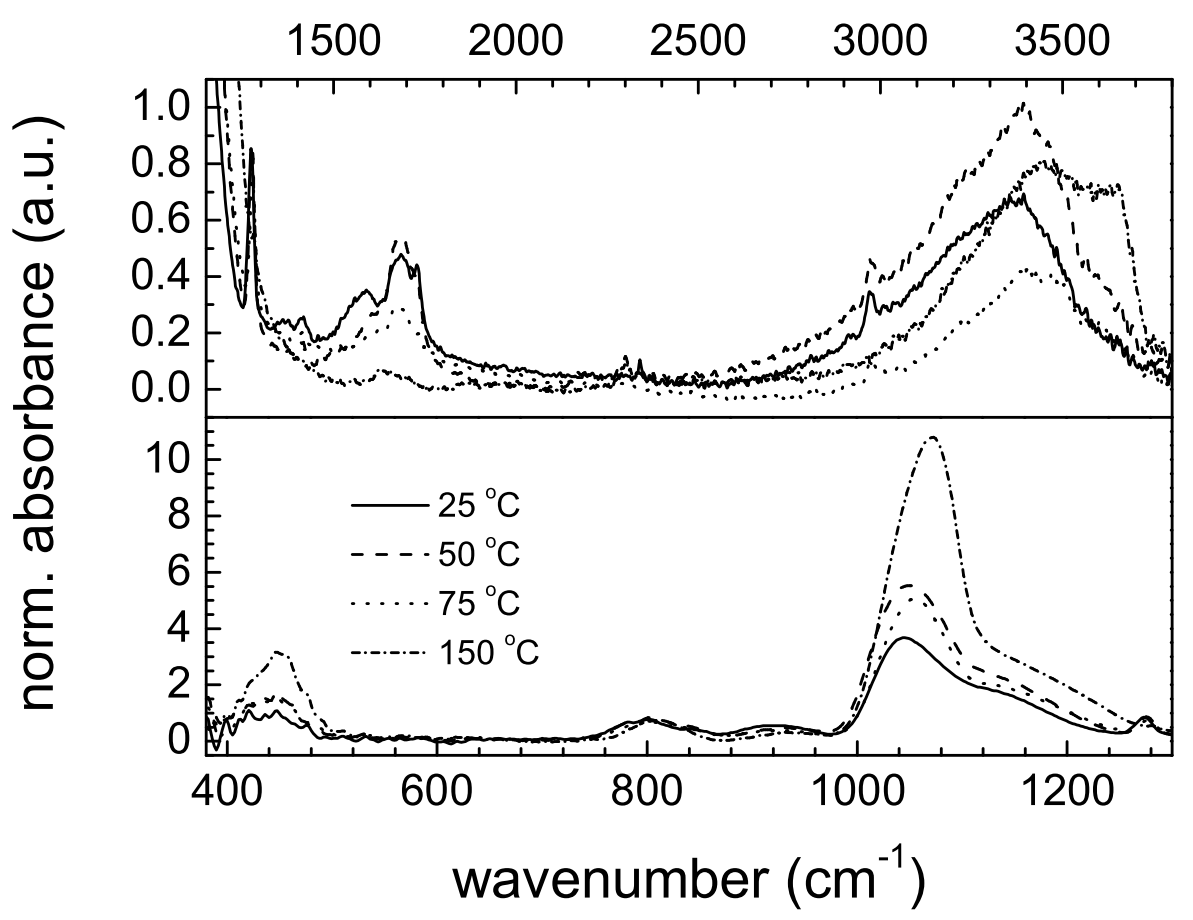

Figure 2. Infrared absorbances of thin films deposited on Si substrates (air flow rate of $6 \mathrm{sccm}$ through liquid HMDSO) for different substrate temperatures (given in figure legend). 


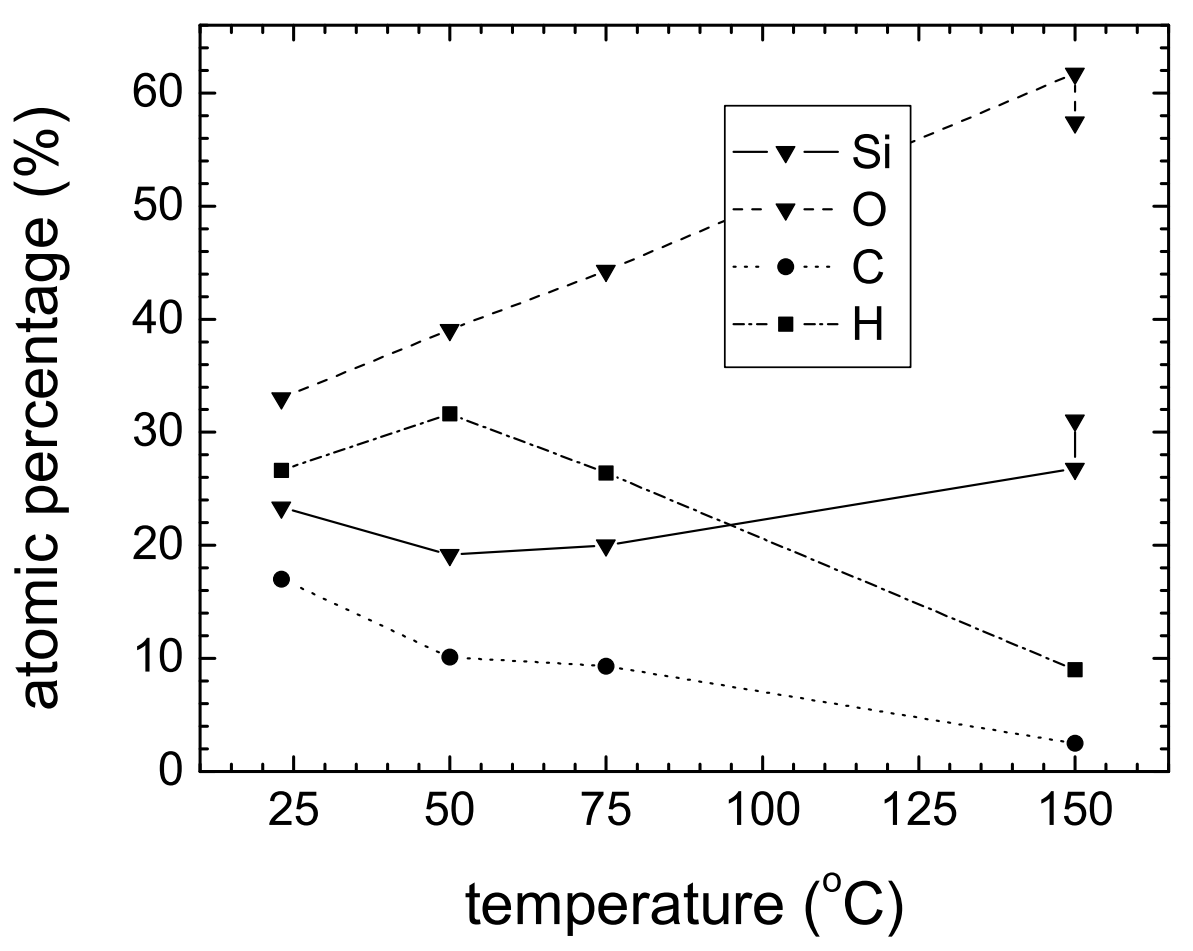

Figure 3. Elemental composition of thin films deposited on Si substrates (air flow rate of $6 \mathrm{sccm}$ through liquid HMDSO) obtained from RBS/ERDA measurements.

The $\mathrm{O} / \mathrm{Si}$ ratio determined from RBS measurements as 1.4 for $25^{\circ} \mathrm{C}$ increased to 2.0 for $50^{\circ} \mathrm{C}$ and even 2.2 and 2.3 for 75 and $150^{\circ} \mathrm{C}$, respectively. Obviously, not all oxygen atoms were bonded in the $\mathrm{Si}-\mathrm{O}-\mathrm{Si}$ network. The presence of $\mathrm{OH}$ groups was evidenced by a broad peak ranging from 3000 to $3750 \mathrm{~cm}^{-1}$. It composed of two peaks centered approximately at 3350 and $3600 \mathrm{~cm}^{-1}$ associated with the stretching of hydrogen-bonded and free O-H groups, respectively [35]. Further evidence of $\mathrm{OH}$ groups comes from the peak at $930 \mathrm{~cm}^{-1}$ assigned to $\mathrm{Si}-\mathrm{OH}$ stretching [32]. The shift of this peak to $920 \mathrm{~cm}^{-1}$ for $25^{\circ} \mathrm{C}$ could be caused by the presence of the peak at $890 \mathrm{~cm}^{-1}$ corresponding to $\mathrm{CH}_{3}$ rocking or Si-C stretching in Si- $\left(\mathrm{CH}_{3}\right)_{2}$ [31, 33]. Additional peaks in the region 1490-1780 $\mathrm{cm}^{-1}$ observed mainly for low temperatures were also associated with non-silica oxygen. The peaks were relatively well resolved for $25^{\circ} \mathrm{C}$ at $1585 \mathrm{~cm}^{-1}$, $1680 \mathrm{~cm}^{-1}$ and $1728 \mathrm{~cm}^{-1}$. These positions were assigned to carboxylate ion, trapped water and carbonyl group, respectively [36, 37, 38]. Presence of $\mathrm{CO}$ and $\mathrm{OH}$ groups can be explained by incorporation of by-products formed during oxidation of HMDSO. Existence of these by-products was proven for low pressure deposition. An increase of optical emission of $\mathrm{OH}$ and $\mathrm{CO}$ was observed when oxygen was added to HMDSO [30] and mass spectrometer revealed the presence of $\mathrm{CO}$ and $\mathrm{CO}_{2}$ in exhaust gas [39].

As already mentioned, the mass and molar densities determined from RBS using 


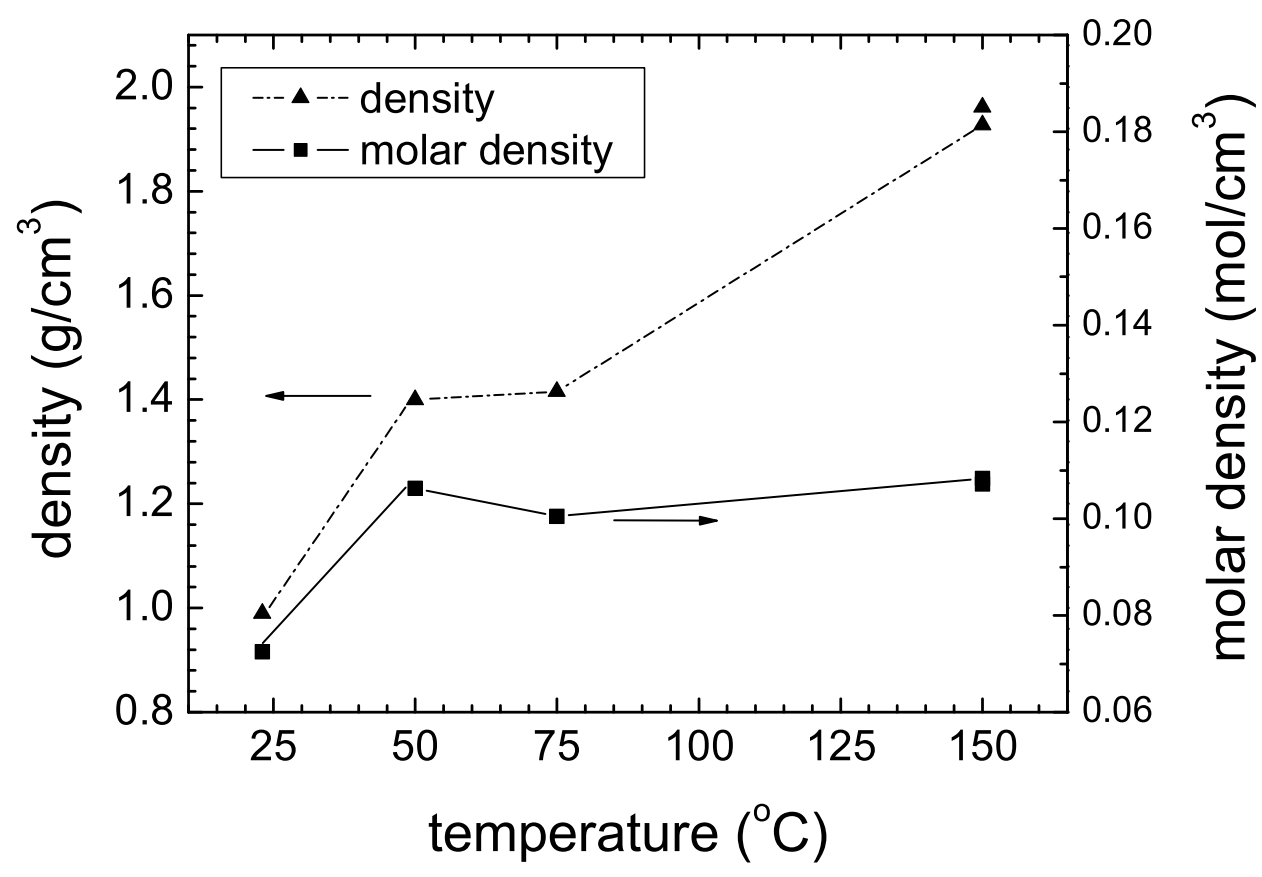

Figure 4. Mass and molar densities of thin films deposited on Si substrates (air flow rate of $6 \mathrm{sccm}$ through liquid HMDSO) obtained from RBS measurements and known film thickness determined by optical methods in UV/VIS/NIR.

known film thicknesses exhibited an increase when the deposition temperature was raised from 25 to $50^{\circ} \mathrm{C}$ and a further temperature increase led to a continuous increase of the mass density (figure 4). The latter effect was rather related to the reduction of hydrogen than to the closer packing of atoms as seen from the constant value of the molar density and rapid decrease of hydrogen content illustrated in figure 3.

3.2.2. Films on glass substrates - air flow rate of $16 \mathrm{sccm}$ The apparent differences between the films on glass and $\mathrm{Si}$ substrates were caused by different instrumentation used for the investigation of their chemical composition. The striking differences between RBS/ERDA (figure 3) and XPS results (figure 5), i. e. differing amount of Si, O and C as well as progressive changes of the composition with the deposition temperature, were caused by the fact that the amount of hydrogen could not be determined by XPS. If the RBS/ERDA results were recalculated without taking into account the hydrogen, the atomic composition of the films deposited on $\mathrm{Si}$ at temperatures 50,75 and $150^{\circ} \mathrm{C}$ would be very similar to the XPS results obtained after the film sputtering. The sputtering was necessary because it removed carbon contamination of the film surface. This fact is supported by RBS analyses of the films on $\mathrm{Si}$ in which the carbon content also rapidly decreased to 2.5 at. $\%$ for the temperature of $150^{\circ} \mathrm{C}$. In agreement with $\mathrm{RBS}$ the incorporation of nitrogen in the films was below 2 at.\%. 


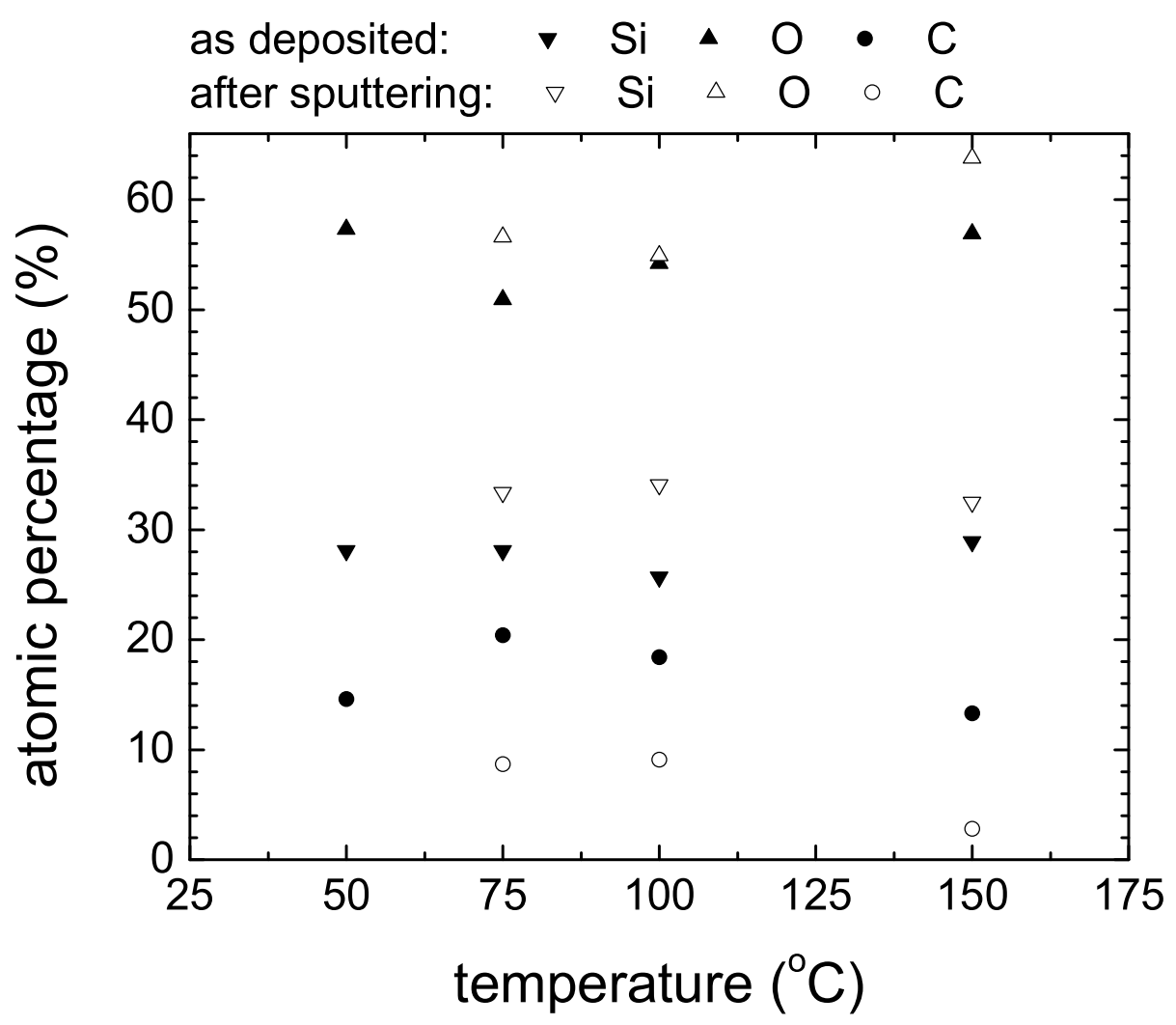

Figure 5. Elemental composition of thin films deposited on glass substrates (air flow rate of $16 \mathrm{sccm}$ through liquid HMDSO) obtained from XPS measurement.

The position of Si $2 p$ XPS atomic signal, corrected for a sample charging, corresponded to the binding energy (BE) of silicon oxides, 103.0-103.5 eV [40, 41, 42]. The corrections were performed by shifting the whole spectra to $285.0 \mathrm{eV}$ of $\mathrm{C} 1 \mathrm{~s}$ signal. More detailed analyses of chemical bonding were obtained by peak fitting of high resolution measurements of the $\mathrm{C} 1 \mathrm{~s}$ signals for the as-deposited samples. The peaks were clearly asymmetric towards higher BE because of oxygen bonded to carbon. A small peak related to these bonds was fitted at about $286.3 \mathrm{eV}$.

The FTIR-ATR spectra of the films deposited on glass at the same temperatures are shown in figure 6. Since ATR measurements were restricted to the range above $530 \mathrm{~cm}^{-1}$, only two of three characteristic absorption bands of silicon oxides could be observed. Moreover, the ATR spectra are strongly influenced by the changes of refractive index around the position of strong absorption peaks and, therefore, these peaks are shifted to lower wavenumbers and any close peaks at lower wavenumbers increase in intensity. These effects caused distortion of the FTIR-ATR spectra, when compared to FTIR transmittances, in the region of strong absorption bands of silicon oxides. The peak of Si-O-Si rocking vibrations was observed at $790 \mathrm{~cm}^{-1}$, i. e. shifted to lower wavenumbers 
by $10-20 \mathrm{~cm}^{-1}$ with respect to the position observed in transmittances of the films on Si. Similarly, the antisymmetric stretching peak moved to lower wavenumbers by approximately $20 \mathrm{~cm}^{-1}$. Its shift from 1020 to $1050 \mathrm{~cm}^{-1}$ was again related to the increased deposition temperature and the possible reasons have already been discussed in details for the films on Si.

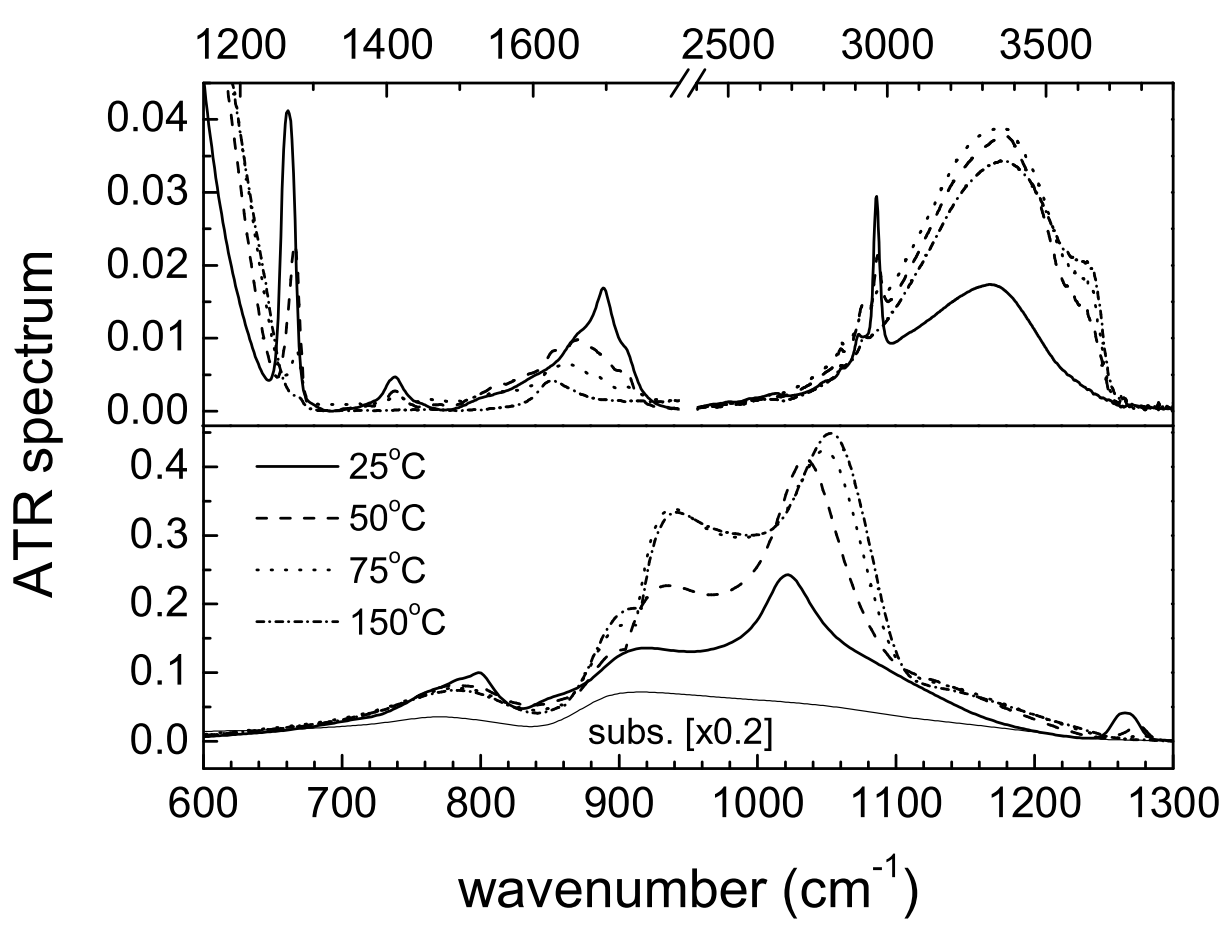

Figure 6. ATR spectra of thin films deposited on glass substrates (air flow rate of $16 \mathrm{sccm}$ through liquid HMDSO) for different substrate temperatures.

The stretching peak of the glass substrate was observed at very low wavenumber, $910 \mathrm{~cm}^{-1}$, and could be seen also in the spectra of the films as a weak shoulder at about $900 \mathrm{~cm}^{-1}$. The relatively strong peak observed at $920-940 \mathrm{~cm}^{-1}$ was associated to Si-OH groups. Its high intensity, compared to transmittances of the films on $\mathrm{Si}$, was caused by the adjacent strong Si-O-Si stretching peak. Other absorption features and their behaviour were similar as in the case of the films on Si. The absorption related to $\mathrm{OH}$ groups was also detected in the region $3000-3700 \mathrm{~cm}^{-1}$. At temperatures above $25^{\circ} \mathrm{C}$, some $\mathrm{OH}$ groups were not hydrogen-bonded as evidenced by the appearance of second peak at higher frequencies, about $3600 \mathrm{~cm}^{-1}$. Absorption in the range $3300-3500 \mathrm{~cm}^{-1}$ could be influenced also by a presence of N-H stretching [35], but since the concentration of nitrogen determined by XPS was below $2 \%$, its contribution was disregarded.

The presence of $\mathrm{CH}_{3}$ groups, reminiscent of original HMDSO reactant, was 
significant especially at lower temperatures. As discussed for the films on $\mathrm{Si}$, their fingerprints were the peaks at $1265-1277 \mathrm{~cm}^{-1}$ and $1412 \mathrm{~cm}^{-1}$. The $\mathrm{C}-\mathrm{H}$ stretching absorption was also detected in the region $2830-3000 \mathrm{~cm}^{-1}$ as three sharp peaks. Presence of additional groups, that do not have their origin in HMDSO, was revealed by a multipeak absorption in the range $1520-1750^{\circ} \mathrm{C}$. It corresponded to several chemical groups such as carboxylate ion, trapped water and carbonyl groups (see above).

\subsection{Film optical properties in UV/VIS/NIR range and deposition rate}

The UV/VIS/NIR optical properties and thickness of the films deposited on $\mathrm{Si}$ using $6 \mathrm{sccm}$ of air bubbling through liquid HMDSO were obtained from combined ellipsometry and reflectometry. Measured data were fitted using a similar dispersion model of the optical constants as in [13]. The model took into account an absorption in the UV range resulting from interband transitions, existence of localized states inside the band gap and a phonon absorption in IR. The interband transitions were described using three parameters (i) band gap $E_{\mathrm{g}}$, (ii) maximum energy limit of interband transitions $E_{\mathrm{h}}$ and (iii) parameter proportional to the total density of states $A$. The transitions corresponding to the localized states as well as the phonon absorption were both parameterized by Gaussian broadened peaks. For details see [43]. Sample imperfections such as non-uniformity and roughness were also taken into account.

The average film thickness obtained from the fitting was used for the calculation of deposition rate plotted in figure 7 . The deposition rate on $\mathrm{Si}$ decreased quadratically with the deposition temperature. It was quite low as compared to the values reported e. g. by Massines et al [17] because 4 ppm of HMDSO in their gas mixture resulted in three times higher deposition rate. However, deposition rate is a function of several parameters including a local supply of depleted precursor molecules that needs to be optimized in our experimental set-up.

The optical properties, refractive index and extinction coefficient, are given in figure 8 and figure 9. The refractive index did not exhibit any monotonic dependence on the temperature. Its value at $632 \mathrm{~nm}$ ranged from 1.45 to 1.47. The film absorption in UV range evidently decreased with the temperature. The extinction coefficient at $200 \mathrm{~nm}$ was in the range $0.014-0.030$ for the films deposited at $23-75^{\circ} \mathrm{C}$. It decreased down to 0.007 for $100^{\circ} \mathrm{C}$ and even more to 0.001 for 120 and $150^{\circ} \mathrm{C}$. Therefore, the material deposited at higher temperatures approaches the structure of $\mathrm{SiO}_{2}$ as already suggested by the results of the previous section.

\subsection{Film mechanical properties}

In case of the indentation tests on thin films, the measured properties depend on the indentation depth due to the combined response of the coating and the substrate (here glass, silicon or polycarbonate). Therefore, the measured elastic modulus and hardness values should be corrected for the substrate influence [44]. In the case of glass and silicon substrates, the elastic modulus and the plastic hardness of the films were lower 


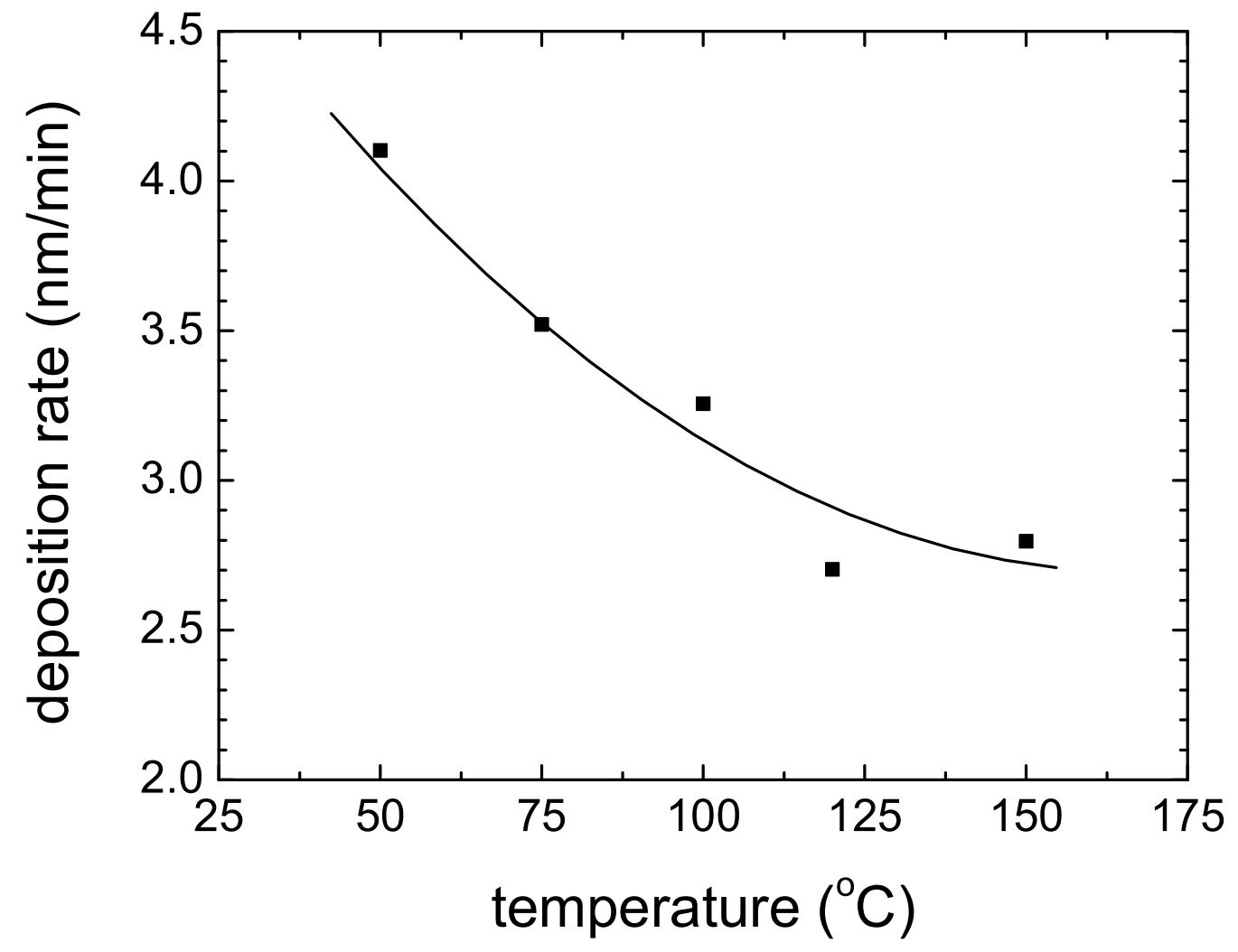

Figure 7. Deposition rates for different substrate temperatures.

than those of the substrate and their values could be calculated using the approach of Oliver and Pharr [45], if the indentation depth does not exceed approx. $10 \%$ of the film thickness. The resulting film elastic modulus and plastic hardness increased with increasing deposition temperature approaching the mechanical properties of $\mathrm{SiO}_{2}$ in the temperature range $120-150^{\circ} \mathrm{C}$. The film microhardness in dependence on temperature is depicted in figure 10 .

In the case of films on polycarbonates, the hardness and elastic modulus of film were always substantially higher than those of the substrate. Therefore, it represented the system of a thin hard coating deposited on a soft viscoelastic-plastic substrate (polycarbonate) and the conditions of the Oliver and Pharr method were not fulfilled. The Martens hardness (HM) that measures both elastic and plastic resistances against indentation was more suitable for the characterisation of the film/substrate systems. The dependencies of HM on indentation depth for the films deposited at several different deposition temperatures are shown in figure 11. According to this figure, the surface hardness of the polycarbonate after nitrogen plasma treatment slightly decreased. The films deposited at elevated temperatures, on the other hand, substantially increased its surface hardness. The trend in the mechanical properties with increasing deposition temperature was similar as for the glass and Si substrates. The films deposited at the maximum temperature suitable for polycarbonate substrates, i. e. $120^{\circ} \mathrm{C}$, exhibited 


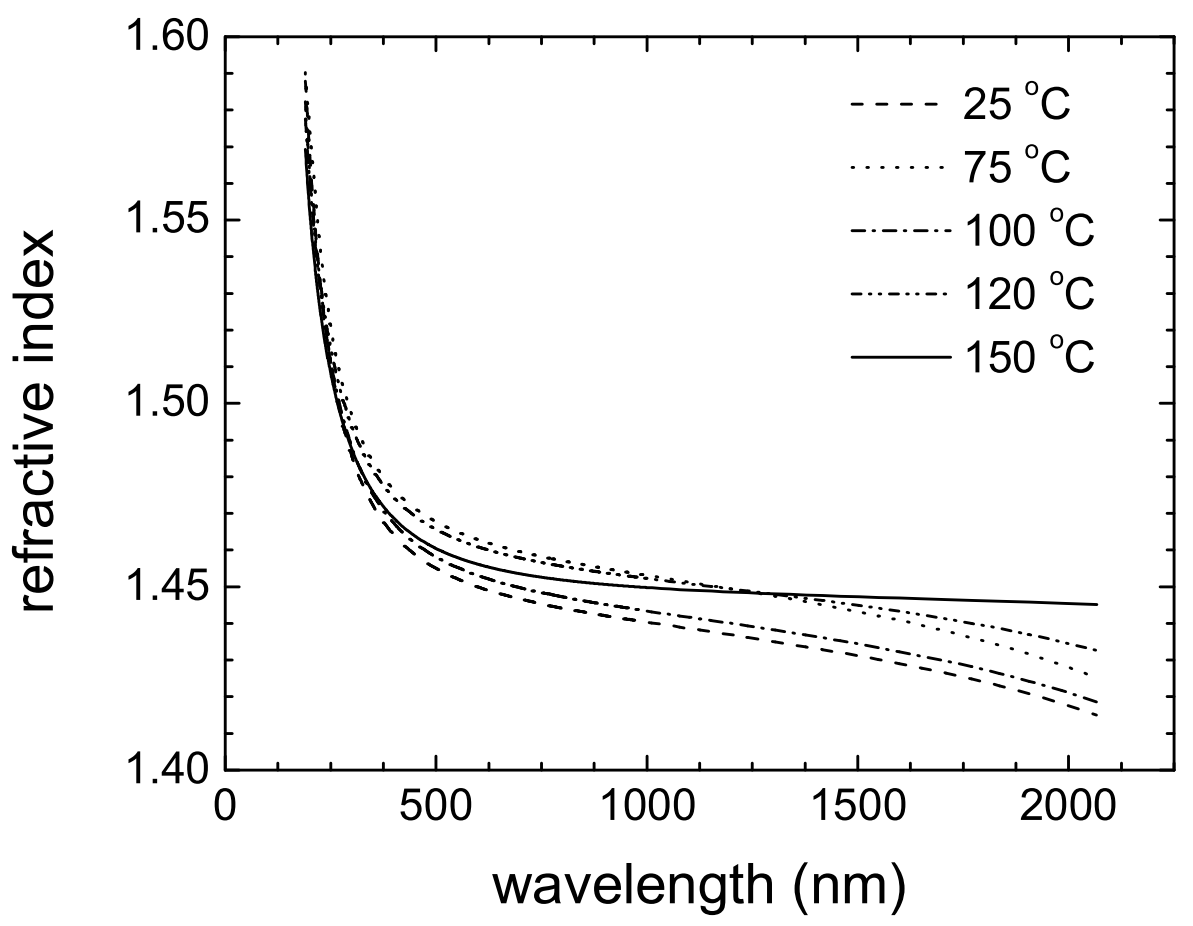

Figure 8. Refractive index of the films deposited on silicon substrates.

mechanical properties very close to $\mathrm{SiO}_{2}$. However, crack creations were observed at higher indentation depths as shown in figure 11. The crack creation may be suppressed by deposition of film with graded structure increasing the temperature during the deposition (i.e. with gradual change of film properties from polymer-like to $\mathrm{SiO}_{2}$ ) $[46,47]$.

\section{Conclusion}

The plasma enhanced CVD of silicon oxide thin films was investigated in atmospheric pressure Townsend-like discharge burning in nitrogen. The films were deposited from the mixture of hexamethyldisiloxane (HMDSO) with oxygen in nitrogen working gas on glass, silicon and polycarbonate substrates. The substrate temperature, varied from $25^{\circ} \mathrm{C}$ to $150^{\circ} \mathrm{C}$, had significant influence on the film's chemical structure and functional properties. The increasing deposition temperature resulted in a decreasing content of carbon and hydrogen and an increasing oxygen-to-silicon ratio in the films. This ratio reached 2.3 for $150^{\circ} \mathrm{C}$ but not all the oxygen atoms were bonded in the Si-O-Si network as revealed by the presence of $\mathrm{OH}$ groups in the FTIR spectra. The hardness of the films on the glass and silicon substrates increased with increasing substrate temperature from $0.4 \mathrm{GPa}$ to $7 \mathrm{GPa}$. Increasing temperature caused increased hardness also for the 


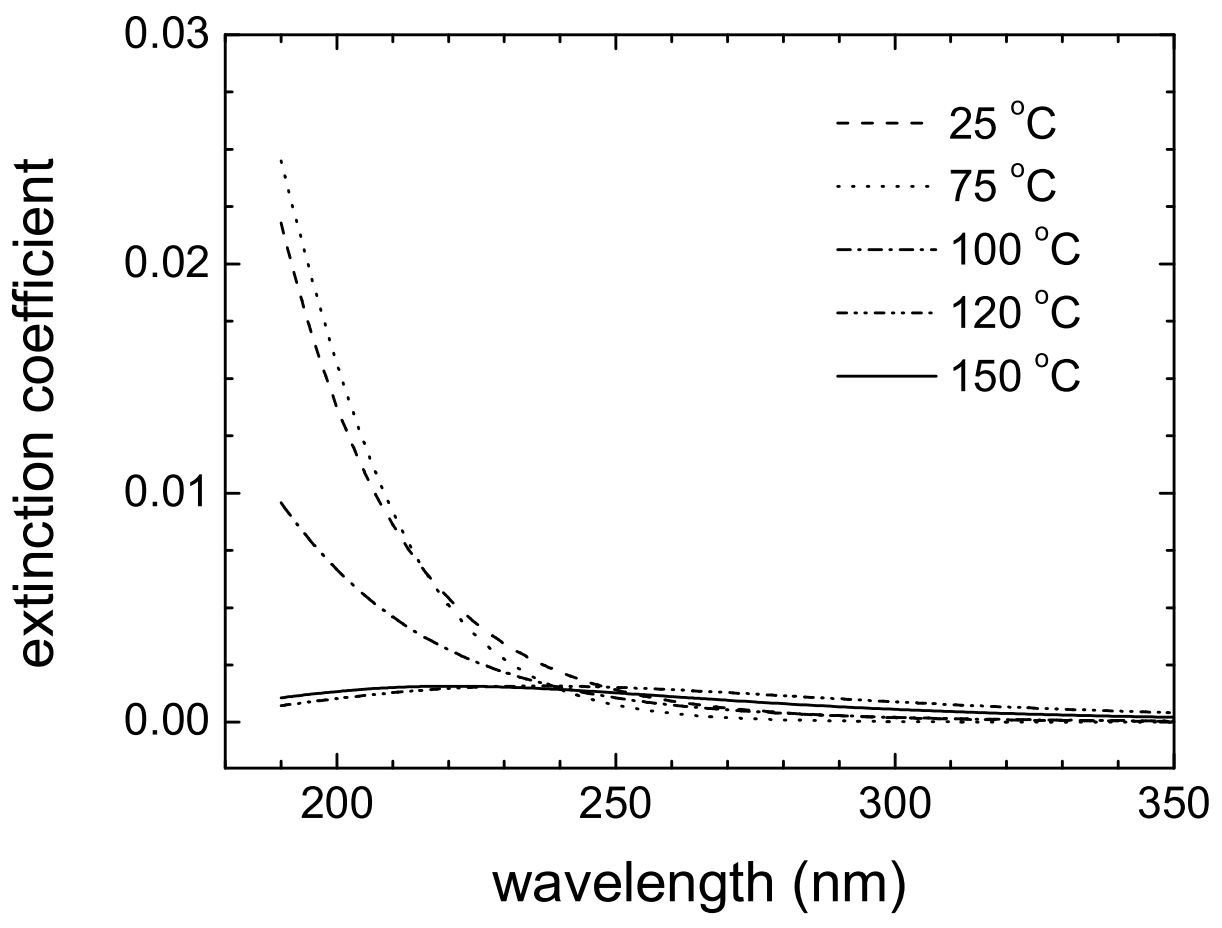

Figure 9. Extinction coefficient of the films deposited on silicon substrates.

films on polycarbonate substrates. The Martens hardness of the film/polycarbonate system for the deposition temperature of $120^{\circ} \mathrm{C}$ was several times higher than this of bare polycarbonate at small indentation depths. The deposition rate decreased with increasing temperature from $5 \mathrm{~nm} \mathrm{~min}{ }^{-1}$ at $25^{\circ} \mathrm{C}$ to $2.8 \mathrm{~nm} \mathrm{~min} \mathrm{mi}^{-1}$ at $150^{\circ} \mathrm{C}$. However, the chemical structure, optical and mechanical properties of the films deposited at $150^{\circ} \mathrm{C}$ approached those of $\mathrm{SiO}_{2}$ films deposited in low pressure discharges [12, 48].

\section{Acknowledgments}

The present work was supported by the Ministry of Education of the Czech Republic under contract MSM0021622411 and by Institutional Research Plan No. AV0Z10100521 and by the Czech Science Foundation under contract 104/09/H080. The authors are grateful to M Kunovský for his technical help.

\section{References}

[1] Kanazawa S, Kogoma M, Moriwaki T and Okazaki S 1988 J. Phys. D: Appl Phys. 21838

[2] Trunec D, Brablec A and Buchta J 2001 J. Phys. D: Appl. Phys. 341697

[3] Gherardi N, Gouda G, Gat E, Ricard A and Massines F 2000 Plasma Sources Sci. Technol. 9340

[4] Sawada Y, Ogawa S and Kogoma M 1995 J. Phys. D: Appl Phys. 281661 


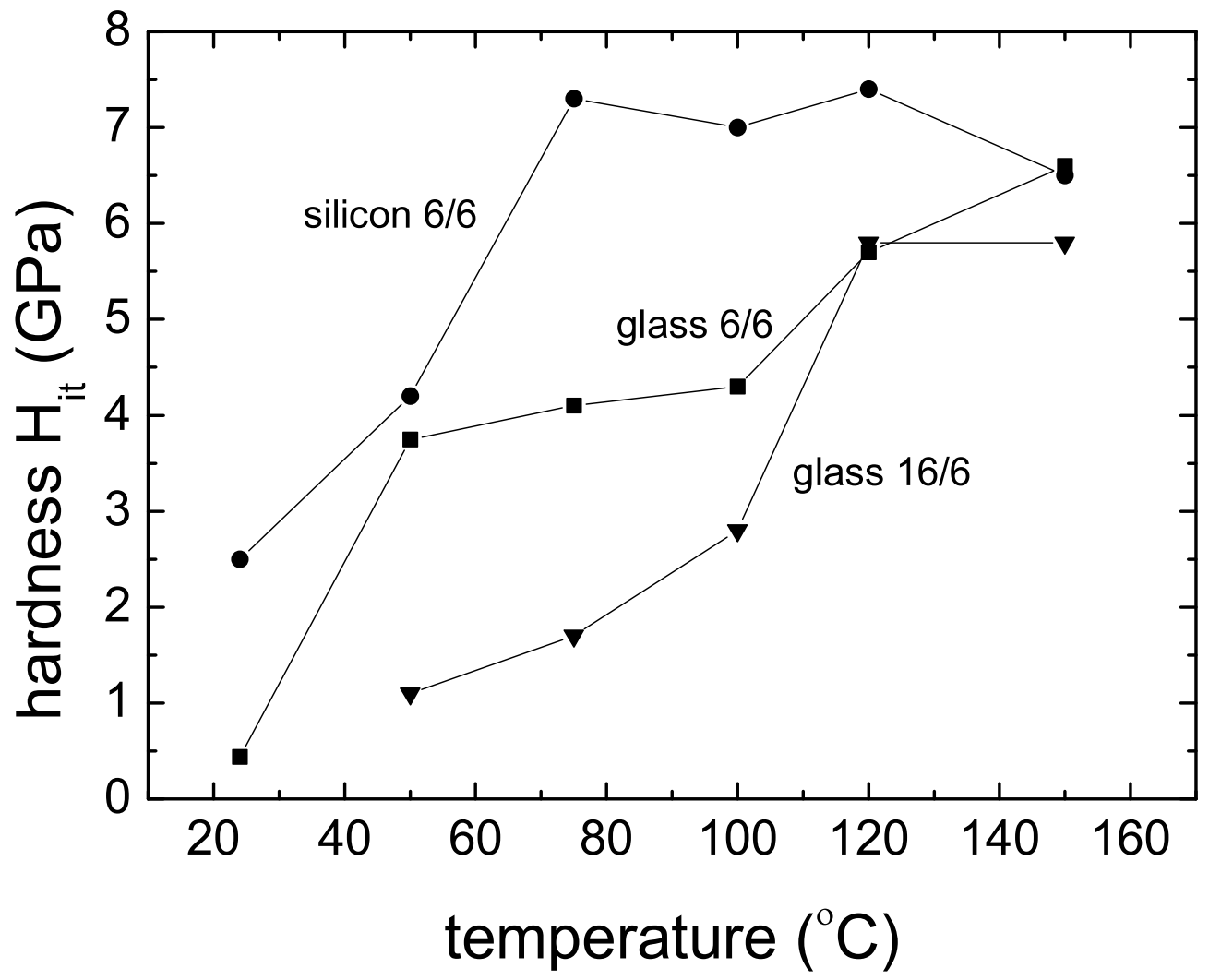

Figure 10. The film microhardness for different deposition conditions. The numbers at curves indicate air flow in sccm / nitrogen flow in slm during the deposition.

[5] Prat R, Koh Y J, Babukutty Y, Kogoma M, Okazaki S and Kodama M 2000 Polymer 417355

[6] Gherardi N, Martin S and Massines F 2000 J. Phys. D: Appl Phys. 33 L104

[7] Foest R, Adler F, Sigeneger F and Schmidt M 2003 Surf. Coating Technol. 163-164 323

[8] Starostine S, Aldea E, de Vries H, Creatore M and van de Sanden M. C. M. 2007 Plasma Process. Polym. 4 S440

[9] Massines F, Gherardi N, Naude N and Segur P 2009 Eur. J. Phys. - Appl. Phys. 4722805

[10] Aldea E, Peeters P, de Vries H and van de Sanden M C M 2005 Surf. Coat. Technol. 20046

[11] Wrobel A M and Wertheimer M R 1990 Plasma Deposition, Treatment and Etching of Polymers ed. R d'Agostino (New York: Academic Press)

[12] Zajíčková L, Buršíková V, Kučerová Z, Franta D, Dvořák P, Šmíd R, Peřina V and Macková A 2007 Plasma Sources Sci. Technol. 16 S123

[13] Zajíčková L, Buršíková V, Franta D, Bousquet A, Granier A, Goullet A and Buršík J 2007 Plasma Process. Polym. 4 S287

[14] Sonnenfeld A, Tun T M, Zajíčková L, Kozlov K V, Wagner H-E, Behnke J F and Hippler R 2001 Plasmas and Polymers 6266

[15] Trunec D, Navrátil Z, Sťahel P, Zajíčková L, Buršíková V and Čech J 2004 J. Phys. D: Appl. Phys. 372112

[16] Čech J, Sťahel P, Šíra M, Buršíková V, Navrátil Z, Trunec D and Brablec A 2005 Chemicke listy 99444

[17] Massines F, Gherardi N, Fornelli and Martin S 2005 Surf. Coat. Technol. 2001855

[18] Caquineau H, Enache I, Gherardi N, Naudé N and Massines F 2009 J. Phys. D: Appl. Phys. 42 


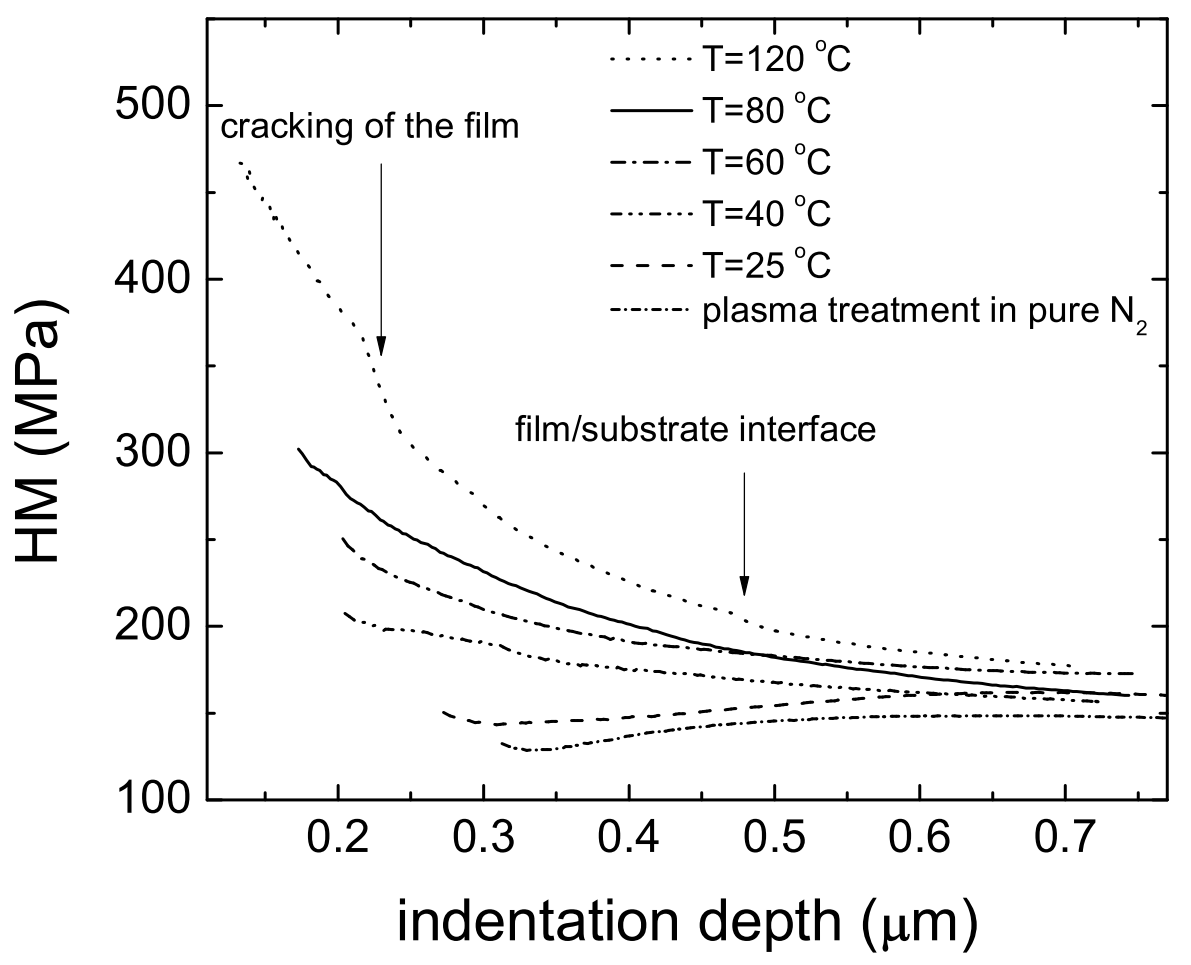

Figure 11. The Martens hardness of films on polycarbonate at different deposition temperatures using air flow rate of $16 \mathrm{sccm}$ compared with the Martens hardness of polycarbonate treated in nitrogen plasma.

125201

[19] Š́ra M 2009 PhD thesis (Brno: Masaryk University) http://is.muni.cz/th/13705/prif_d/disis.muni.cz.pdf p. 78

[20] Saarilahti J and Rauhala E 1992 Nucl. Instr. and Meth. B B64 734

[21] Mayer M 1997 SIMNRA User's Guide, Report IPP 9/113 (Garching: Max-Planck-Institut fuer Plasmaphysik)

[22] Ohlídal I and Franta D 2000 Progress in Optics vol 41 (Amsterdam: Elsevier)

[23] Martinet C and Devine R A B 1995 J. Appl. Phys. 774343

[24] He L, Inokuma T, Kurata Y and Hasegawa S 1995 J. Non-Crystall. Solids 185249

[25] Kučírková A, Navrátil K, Pajasová L and Vorlíček V 1996 Appl. Phys. A 63495

[26] Devine R A B 1992 Trans. Mater. Res. Soc. Jpn. 8165

[27] Kashiwagi K, Yoshida Y and Murayama Y 1991 Jap. J. Appl. Phys. 301803

[28] Durrant S F, Mota R P and de Moraes M A B 1996 Vacuum 47187

[29] Kim M T 1997 Thin Solid Films 311157

[30] Aumaille K, Vallée C, Granier A, Goullet A, Gaboriau F and Turban G 2000 Thin Solid Films 359188

[31] Rau C and Kulisch W 1994 Thin Solid Films 24928

[32] Lamendola R, D'Agostino R and Fracassi F 1997 Plasmas and Polymers 2147

[33] Anderson D R 1974 Analysis of Silicones (New York: Wiley-Interscience) 
[34] Dischler B, Bubenzer A and Koidl P 1983 Solid State Commun. 48105

[35] Mayo D, Miller F A and Hannah R W 2004 Course Notes on the Interpretation of Infrared and Raman Spectra (New York: Wiley-Interscience) chap 6

[36] Mayo D, Miller F A and Hannah R W 2004 Course Notes on the Interpretation of Infrared and Raman Spectra (New York: Wiley-Interscience) p 210

[37] http://webbook.nist.gov/cgi/cbook.cgi?ID=C7732185\&Units=SI\&Mask=80 (December 2009).

[38] Mayo D, Miller F A and Hannah R W 2004 Course Notes on the Interpretation of Infrared and Raman Spectra (New York: Wiley-Interscience) chap 7

[39] Alexander M R, Jones F R and Short R D 1997 Plasmas and Polymers 2277

[40] Alexander M R, Short R D, Jones F R, Stollenwerk J Z M and Michaeli W 1996 J. Mater. Sci. 311879

[41] Gengenbach T R and Griesser H J 1999 Polymer 405079

[42] Moulder J F, Sticle W F, Sobol P E and Bomben K D 1992 Handbook of X-ray Photoelectron Spectroscopy (Eden Prairie: Perkin-Elmer Co.)

[43] Franta D, Nečas D and Zajiččková L 2007 Optics Express 1516230

[44] Battacharya A K and Nix W D 2001 Int. J. Solids Struct 38335

[45] Pharr G M, Oliver W C and Brotzen F R 1992 J. Mater. Res. 7613

[46] Schulz U and Kaiser N 2006 Prog. Surf. Sci. 81387

[47] Poitras D and Martinu L 2000 Appl. Opt. 391168

[48] Zajíčková L, Buršíková V, Kučerová Z, Franclová J, Sťahel P, Peřina V and Macková A 2007 J. Phys. Chem. Solids 681255 